MATEC Web of Conferences 6, 03002 (2013)

DOI: $10.1051 /$ matecconf $/ 20130603002$

(C) Owned by the authors, published by EDP Sciences, 2013

\title{
Prediction of fire spalling in fibre-reinforced high strength concrete
}

\author{
R.B. Mugume ${ }^{1}$ and T. Horiguchi ${ }^{2}$ \\ ${ }^{1}$ Graduate Student, Environmental Material Engineering Laboratory, Hokkaido University, \\ Sapporo, Japan \\ ${ }^{2}$ Associate Professor, Environmental Material Engineering Laboratory, Hokkaido University, \\ Sapporo, Japan
}

\begin{abstract}
This paper presents results of a study which investigates spalling in small scale specimens of fibre-reinforced high strength concrete exposed to elevated temperatures. A relationship to predict relative maximum pressures was developed, which takes into account parameters such as concrete strength, fibre type and fibre geometry. Also, a blowtorch spalling test method was utilized to investigate spalling in small scale specimens, and a clear relationship between relative maximum pore pressures and spalling was observed.
\end{abstract}

\section{INTRODUCTION}

Prediction of the spalling behavior of concrete when exposed to high temperaturesis one of the most important challenges faced by engineers dealing with the design and construction of concrete structures worldwide. Pore pressure spalling, which occurs as a result of the build-up of pore pressure inside heated concrete, has been studied by many researchers as one of the important mechanisms of explosive spalling [1-3]. However, limited experimental studies have been conducted to determine the maximum pore pressures that can be tolerated in heated concrete without spalling occurring, and hence being able to predict the likelihood of spalling. Since pore pressure spalling has been found to be fundamental to the phenomenon of explosive spalling, developing a relationship between maximum pore pressures and spalling is key to predicting spalling in concrete exposed to elevated temperatures.

Therefore this experimental study is aimed at investigating spalling of fibre-reinforced high strength concrete exposed to severe heating. A relationship between relative maximum pore pressures and spalling was developed, which was used to determine a threshold relative maximum pressure above which spalling will be expected to occur, hence predicting the likelihood of spalling in heated concrete.

\section{EXPERIMENTAL PROCEDURE}

\subsection{Materials and mix proportions}

Nine series of concretes were prepared using OPC (Ordinary Portland Cement) and crushed stone with the maximum nominal size of $13 \mathrm{~mm}$. W/C of 0.5 was used for Normal Strength Concrete (NSC) while W/C of 0.3 was used for the remaining High Strength Concrete (HSC) series. Some parameters of the mix proportion were kept constant for all series: water content of $170 \mathrm{~kg} / \mathrm{m}^{3}$ and sand to aggregate ratio (s/a) of 50\%. Addition of polypropylene (PP) monofilament fibres, polyvinyl alcohol (PVA) fibres, and a combination of PP or PVA with steel fibres i.e. hybrid fibres was the main differentiation of the series.

This is an Open Access article distributed under the terms of the Creative Commons Attribution License 2.0, which permits unrestricted use, distribution, and reproduction in any medium, provided the original work is properly cited. 
Table 1. Characteristics of fibres.

\begin{tabular}{|l|l|l|l|l|}
\hline & Polypropylene & Polyvinyl alcohol & Steel $(\mathrm{S} 13)$ & Steel $(\mathrm{S} 30)$ \\
\hline Diameter $(\mathrm{mm})$ & $0.018,0.028$ & $0.016,0.040$ & 0.16 & 0.60 \\
\hline Length $(\mathrm{mm})$ & 6,12 & 6 & 13 & 30 \\
\hline Shape & Filament & Filament & Straight & Indent \\
\hline Density $\left(\mathrm{gr} / \mathrm{cm}^{3}\right)$ & 0.9 & 1.3 & 7.8 & 7.8 \\
\hline $\mathrm{T}_{\text {melt }}\left({ }^{\circ} \mathrm{C}\right)$ & $160-170$ & $200-230$ & 1370 & 1370 \\
\hline $\mathrm{T}_{\text {vaporize }}\left({ }^{\circ} \mathrm{C}\right)$ & 341 & - & - & - \\
\hline
\end{tabular}

Table 2. Mixture proportions.

\begin{tabular}{|c|c|c|c|c|c|c|c|c|c|c|}
\hline \multirow[t]{2}{*}{ Series } & \multirow[t]{2}{*}{$\mathrm{W} / \mathrm{C}(\%)$} & \multirow[t]{2}{*}{ s/a (\%) } & \multicolumn{3}{|c|}{ Fibre vol. (\%) } & $\mathrm{W}$ & $\mathrm{C}$ & $\mathrm{S}$ & G & \multirow[t]{2}{*}{$\operatorname{SPAE}^{* 1}(\% C)$} \\
\hline & & & $\mathrm{PP} / \mathrm{PVA}$ & (S30) & (S13) & \multicolumn{4}{|c|}{$\left(\mathrm{kg} / \mathrm{m}^{3}\right)$} & \\
\hline Plain NSC & 50 & \multirow{9}{*}{50} & - & \multirow[t]{7}{*}{-} & \multirow[t]{7}{*}{ - } & \multirow{9}{*}{170} & 340 & 893 & 867 & \multirow{9}{*}{0.9} \\
\hline Plain HSC & \multirow{8}{*}{30} & & - & & & & \multirow{8}{*}{567} & \multirow{6}{*}{795} & \multirow{6}{*}{771} & \\
\hline PP 6-18 & & & & & & & & & & \\
\hline PP 12-18 & & & & & & & & & & \\
\hline PP 12-28 & & & & & & & & & & \\
\hline PVA 6-16 & & & \multirow{4}{*}{0.1} & & & & & & & \\
\hline PVA 6-40 & & & & & & & & & & \\
\hline HY(PP 6-18) & & & & 0.4 & 0.1 & & & 788 & 764 & \\
\hline HY(PVA 6-40) & & & & 0.4 & 0.1 & & & 788 & 764 & \\
\hline
\end{tabular}

$\operatorname{SPAE} * 1$ : Super plasticizer and air entraining agent.

Two types of steel fibres were used in this experimental study and the fibre properties are as shown in Table 1. A polycarboxylate ether superplasticiser was used at a dosage of $0.9 \%$ of cement content to achieve the desired workability. Concrete mix proportions of all series cast are shown in Table 2 . The convention for naming different series according to fibre type, fibre length and fibre diameter was used. For example HY PP 6-18 is explained as follows: HY means its hybrid concrete containing steel and organic fibres, PP 6-18 mean the organic fibre added is polypropylene (PP) with length of $6 \mathrm{~mm}$ and diameter of $18 \mu \mathrm{m}(0.018 \mathrm{~mm})$.

Cast specimens were $100 \mathrm{~mm}$ in diameter by $200 \mathrm{~mm}$ in height for strength tests and $175 \mathrm{~mm}$ in diameter by $100 \mathrm{~mm}$ in height for pore pressure tests. After casting, the specimens were covered with wet burlap under polyvinyl sheet. After 24 hours, the specimens were demolded and cured under limesaturated water at temperature of $20 \pm 2{ }^{\circ} \mathrm{C}$ for 28 days for strength tests. Pore pressure and spalling test specimens were also cured under the same conditions for about 3 months in order to achieve a homogenous moisture state. The initial moisture content of the specimens was between 5 and $7 \%$ by mass.

\subsection{Experimental set-up for pore pressure measurement}

All specimens tested during the pore pressure measurement experiment were $175 \mathrm{~mm}$ in diameter and $100 \mathrm{~mm}$ in height. Thermal load was applied on one face of the concrete specimen by means of a computer-controlled radiant heater placed $10 \mathrm{~mm}$ above it. The heater of power 500 watts exposes the whole surface of the specimen and generates maximum temperature of up to $600{ }^{\circ} \mathrm{C}$. Ceramic fibre was used to heat-insulate the lateral faces of the specimens to ensure quasi-unidirectional thermal load upon it. A heating rate of $10^{\circ} \mathrm{C} / \mathrm{min}$ was applied in the experiment whereby the specimen was set under the heating device and temperature increased gradually at a rate of $10^{\circ} \mathrm{C} / \mathrm{min}$ until it reaches the maximum temperature of $600^{\circ} \mathrm{C}$. Then this maximum temperature was maintained for 3 hours, after which the heated specimens were left to cool down naturally. 


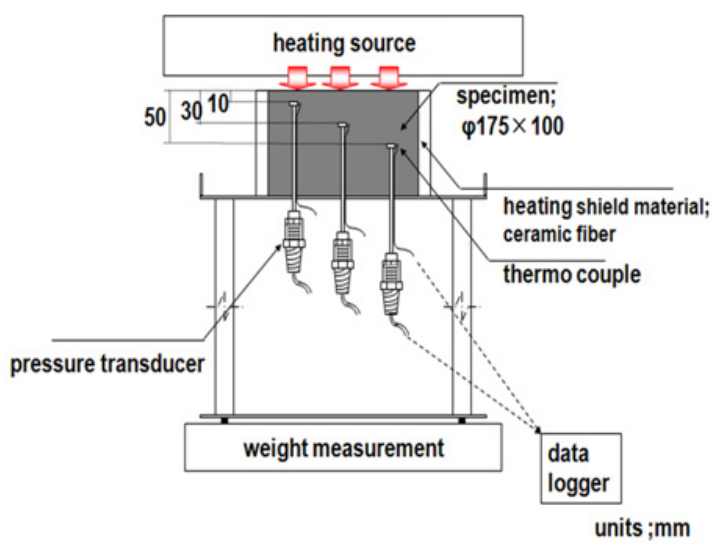

Figure 1. Set-up for pressure measurement.

All specimens were instrumented with pressure gauges that allow pore pressure measurements. The gauges were made of a disk of porous sintered metal $(\oslash 12 \mathrm{~mm} \times 4 \mathrm{~mm})$ with evenly distributed pores of diameter $2 \mu \mathrm{m}$ which was encapsulated into a metal cup that was brazed to a metal tube with inner diameter of $1.5 \mathrm{~mm}$. The free end of the tube then stuck out at the rear face of the specimen. Three gauges were placed with in the central zone of the specimen at 10,30 and $50 \mathrm{~mm}$ respectively, from the heated face. A porous sintered metal is used because it would be able to collect moisture vapour in an evenly manner due to its evenly distributed pores which lead to stable pressure measurements. K-type of thermocouples were attached on the sides of the gauges to measure the temperature inside the heated specimens. An additional thermocouple was placed on the heated surface of the specimen to measure and monitor the build up of temperature. Prior to heating, all gauges were filled with silicon oil having a flash point of $315^{\circ} \mathrm{C}$ and a thermal expansion of $0.00095 \mathrm{cc} / \mathrm{cc} /{ }^{\circ} \mathrm{C}$. The set-up of the experimental test is shown in Figure 1.

\subsection{Experimental set-up for the blowtorch spalling test}

For each test, at least two prism specimens of size $90 \times 150 \times 150 \mathrm{~mm}$ were tested for spalling using a blowtorch test. During the test, un-cut faces of $90 \times 150 \mathrm{~mm}$ were exposed to a flame with the thermal load characterized by a very steep temperature increase during the first minutes of the fire. The blowtorch spalling test set-up is shown in Figure 2, with the nozzle positioned $30 \mathrm{~mm}$ from the surface of the concrete specimen. The blowtorch flame was aimed at the centre of the specimen in order to achieve a uniform distribution of the heat on the specimen. An average heating rate of about $200{ }^{\circ} \mathrm{C} / \mathrm{min}$ was measured, using thermocouples placed on the heated surface. The test was ended once the surface temperature of the heated face of the specimen exceeded $700{ }^{\circ} \mathrm{C}$, since no further spalling was experienced in all the preliminary tests. Different depths of spalling were measured, using a vernier caliper, and an average value was then calculated.

\section{RESULTS AND DISCUSSION}

\subsection{Specimens' Properties}

Fresh and hardened properties of all the series of concrete measured at room temperature are showed in Table 3. It was generally observed that in HSC mixtures, with the exception of PVA $6 \mathrm{~mm}-16$ micron series, addition of fibres in concrete generally reduced the workability of fresh concrete. This behavior may be attributed to the intertwining of the fibres during the concrete mixing process, resulting in 


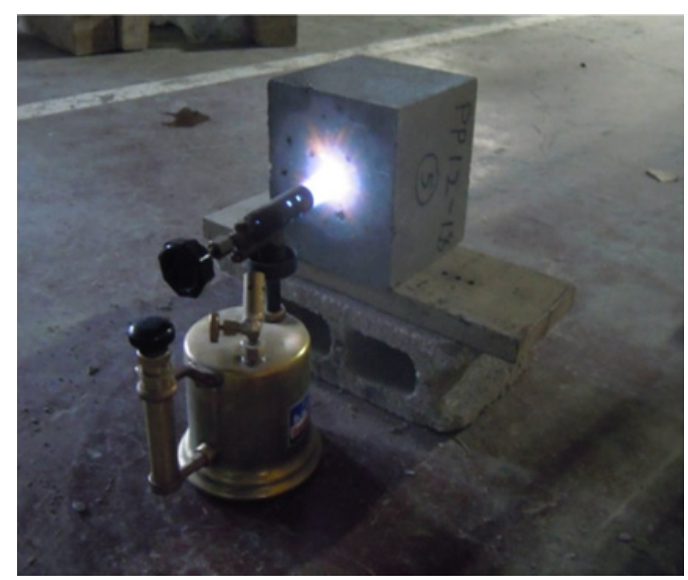

Figure 2. Set-up of a blowtorch spalling test.

Table 3. Fresh and hardened properties of concrete.

\begin{tabular}{|l|c|c|c|c|c|}
\hline & \multicolumn{2}{|c|}{ FRESH PROPERTIES } & \multicolumn{3}{c|}{ HARDENED PROPERTIES } \\
\hline Series & Slump $(\mathrm{mm})$ & Air content $(\%)$ & $\mathrm{f}^{\prime} \mathrm{c}(\mathrm{MPa})$ & $\mathrm{f} \mathrm{t}(\mathrm{MPa})$ & $\mathrm{UPV}(\mathrm{km} / \mathrm{s})$ \\
\hline Plain HSC & 198 & 1.8 & 89.70 & 5.31 & 4.76 \\
\hline Plain NSC & 139 & 4.6 & 32.87 & 3.54 & 4.27 \\
\hline PP 6-18 & 74 & 3.5 & 70.49 & 5.58 & 4.52 \\
\hline PP 12-18 & 47 & 2.6 & 65.41 & 5.73 & 4.57 \\
\hline PP 12-28 & 145 & 4.0 & 66.78 & 5.24 & 4.56 \\
\hline PVA 6-16 & 209 & 1.7 & 79.23 & 5.56 & 4.63 \\
\hline PVA 6-40 & 49 & 1.7 & 69.14 & 5.60 & 4.57 \\
\hline HY(PP 6-18) & 99 & 1.0 & 71.04 & 6.28 & 4.62 \\
\hline HY(PVA 6-40) & 70 & 2.4 & 72.08 & 6.07 & 4.61 \\
\hline
\end{tabular}

a reduction in slump. Also, larger diameter fibres tended to generate more air content in concrete compared to smaller diameters.

\subsection{Prediction of relative maximum pressures in heated concrete}

A relationship to predict relative maximum pressures was developed which takes into account parameters such as concrete strength, fibre type and fibre geometry. The relative predicted maximum pressure $\left(P_{r \cdot p}\right)$ is calculated using the relationship developed by multiple regression analysis as showed below:

$$
P_{r \cdot p}=0.0113 f_{\mathrm{C}}^{\prime}-0.05 T_{f}-0.01 L_{f}-0.0021 S A_{O F}-0.001 S A_{S F}
$$

where $f_{C}^{\prime}$ is the compressive strength of concrete, $T_{f}$ is a constant for type of organic fibre with values of 1 and 0.2 for PP and PVA fibres respectively, $L_{f}$ is length of organic fibres, $S A_{O F}$ is the cumulative surface area of organic fibres and $S A_{S F}$ is the cumulative surface area of steel fibres. $T_{f}$ is dependent on other factors such as bond strength between concrete and fibres, melting point and vaporization of fibres but their effect has not been included in the current relative maximum pressure prediction relationship. Relative maximum pressures are derived from dividing maximum pressures measured for the different types of concrete with the maximum pressure measured in plain HSC e.g. relative maximum pressure in $\mathrm{PP}$ concrete $=($ maximum pressure in PP concrete $/$ maximum pressure in Plain HSC $)$. A relative value of 
IWCS 2013

Table 4. Relative measured and relative predicted maximum pressures.

\begin{tabular}{|c|c|c|c|c|c|}
\hline \multirow[t]{2}{*}{ Series } & \multirow[t]{2}{*}{ Length $(\mathrm{mm})$} & \multirow[t]{2}{*}{ Diameter $(\mathrm{mm})$} & \multicolumn{2}{|c|}{ Measured maximum pressures } & \multirow{2}{*}{$\begin{array}{l}\text { Relative predicted } \\
\text { maximum pressures }\end{array}$} \\
\hline & & & Actual (MPa) & Relative & \\
\hline Plain HSC & - & - & 5.0 & 1 & 1.01 \\
\hline Plain NSC & - & - & 2.1 & 0.41 & 0.37 \\
\hline PP 6-18 & 6 & 0.018 & 1.1 & 0.21 & 0.22 \\
\hline PP 12-18 & 12 & 0.018 & 0.8 & 0.15 & 0.10 \\
\hline PP 12-28 & 12 & 0.028 & 1.1 & 0.22 & 0.28 \\
\hline PVA 6-16 & 6 & 0.016 & 1.5 & 0.31 & 0.30 \\
\hline PVA 6-40 & 6 & 0.040 & 2.9 & 0.58 & 0.50 \\
\hline HY(PP 6-18) & 6 & 0.018 & 0.9 & 0.18 & 0.17 \\
\hline HY( PVA 6-40) & 6 & 0.040 & 2.7 & 0.53 & 0.48 \\
\hline
\end{tabular}

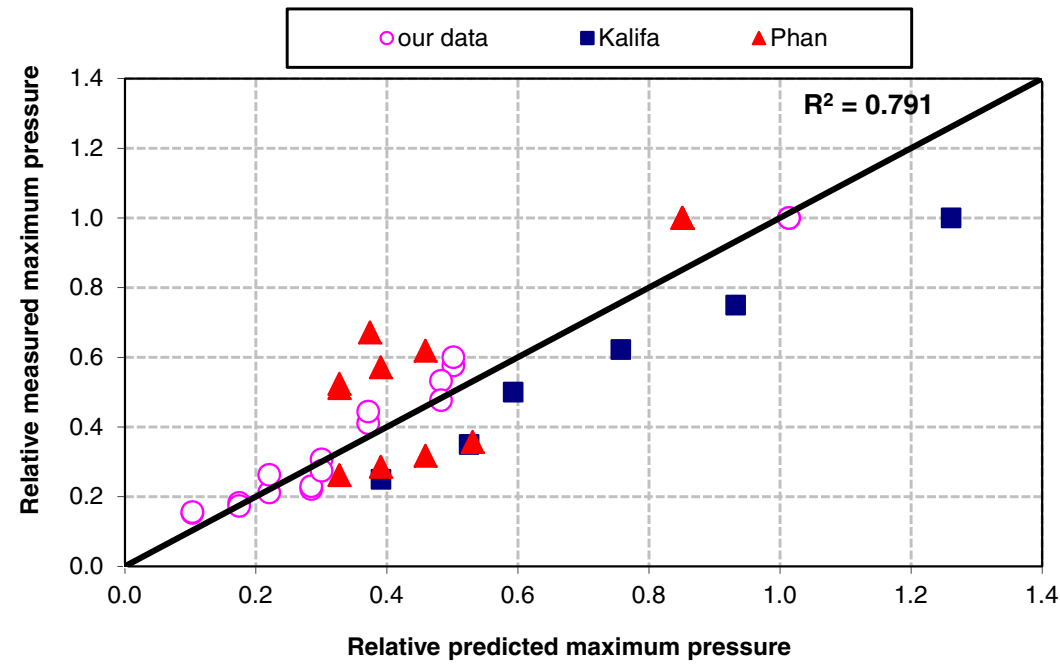

Figure 3. Relationship between relative measured and predicted maximum pressures.

pressure is used instead of the directly measured values in order to minimize the effect of measurement techniques and equipment errors since different researchers use different measurement set-ups.

Values of the relative measured and relative predicted maximum pressures are summarized in Table 4. A comparison between relative measured and relative predicted maximum pressures was carried out, on results from this experimental study [4] and from other researchers [5, 6]. As shown in Figure 3, a strong correlation was observed between the relative measured and predicted maximum pressures from different researchers.

It must however be observed that this relationship for predicting maximum pressures is still a rough one which needs to be further refined through conducting more research to include other parameters such as effect of heating rate, melting and optimal length of organic fibre, bond strength between concrete and fibres, specimen size effect, moisture content etc.

\subsection{Relationship between maximum pore pressure and spalling}

A study aimed at developing a relationship between relative maximum pore pressures and spalling was conducted. A blowtorch spalling test method was utilized to investigate spalling in small scale specimens 
MATEC Web of Conferences

Table 5. Spalling values and measured maximum pressures.

\begin{tabular}{|l|c|c|c|c|}
\hline & & & \multicolumn{2}{|c|}{ Measured maximum pressures*1 } \\
\cline { 3 - 5 } Series & Average spalling depth $(\mathrm{mm})$ & Spalling area $\left(\mathrm{mm}^{2}\right)$ & Actual $(\mathrm{MPa})$ & Relative \\
\hline Plain HSC & 23.15 & 10166 & 5.0 & 1 \\
\hline Plain NSC & 13.18 & 6980 & 2.1 & 0.41 \\
\hline PP 6-18 & 0 & 0 & 1.1 & 0.21 \\
\hline PP 12-18 & 0 & 0 & 0.8 & 0.15 \\
\hline PP 12-28 & 0.11 & 581 & 1.1 & 0.22 \\
\hline PVA 6-16 & 0.22 & 1269 & 1.5 & 0.31 \\
\hline PVA 6-40 & 0.28 & 1512 & 2.9 & 0.58 \\
\hline HY(PP6-18) & 0 & 0 & 0.9 & 0.18 \\
\hline HY(PVA 6-40) & 0.15 & 824 & 2.7 & 0.53 \\
\hline
\end{tabular}

*: Mugume et al. 2012 [4].

of fibre-reinforced high strength concrete exposed to elevated temperatures. Spalling was observed in small unloaded and unrestrained specimens, which almost always do not spall during furnace tests. Since spalling was encountered in the small specimens during the blowtorch spalling test, it is very likely that it will occur on realistic size elements. Therefore this spalling test method provides a promising, effective and economical test method for spalling, at a small scale level on small unloaded and unrestrained specimens, which can help to provide relevant and useful data for mitigation of spalling in realistic size elements.

Furthermore, a clear relationship between the results of relative maximum pore pressures and spalling results was observed, and a threshold relative maximum pore pressure above which spalling is likely to occur was suggested. Table 5 shows the spalling depths measured for the different concrete mixes during the blowtorch test. Based on relative measured maximum pressures previously measured in different fibre-reinforced concrete mixes [4] and the corresponding average spalling depths, as shown in Table 5, a linear relationship for predicting the average spalling depth $\left(D_{s . p}\right)$ in fibre-reinforced concrete was developed. This relationship was obtained as shown in Figure 4, and is presented below:

$$
\begin{aligned}
& D_{s \cdot p}=\left(P_{r \cdot p}-0.183\right) / 1.1701 \\
& \text { If } P_{r \cdot p} \leq 0.183 \text { then } D_{s \cdot p}=0 .
\end{aligned}
$$

It should be noted that this linear relationship does not incorporate Plain concrete (i.e. Plain HSC and NSC) since it encountered severe explosive spalling during this study, as well as in other past studies $[7,8]$. The target is to develop a relationship which can be used to select appropriate organic fibre types and geometries capable of lowering the relative maximum pressures in Plain HSC from a value of 1 to an acceptable threshold value in fibre-reinforced concrete below which no spalling will occur. Thus, as shown in Figure 4, it was observed that occurrence of spalling in fibre-reinforced HSC started above a relative measured maximum pressure of 0.183 and therefore this value could be used as a threshold value in heated concrete above which spalling is most likely to occur. This value is equivalent to an actual maximum pressure of $0.92 \mathrm{MPa}$ in fibre-reinforced high strength concrete.

Figure 5 shows a comparison between actual and predicted average spalling depths and a correlation coefficient of 0.66 was obtained by regression analysis. This shows that there is a fairly good correlation between the actual and predicted average spalling depths. However, further experimental research is required to improve on the average spalling depth prediction relationship, by incorporating some important parameters, such as monitoring and/or modeling of temperature distributions and pore pressures, as well as the analysis of the microstructure of concrete after exposure to elevated temperature. 


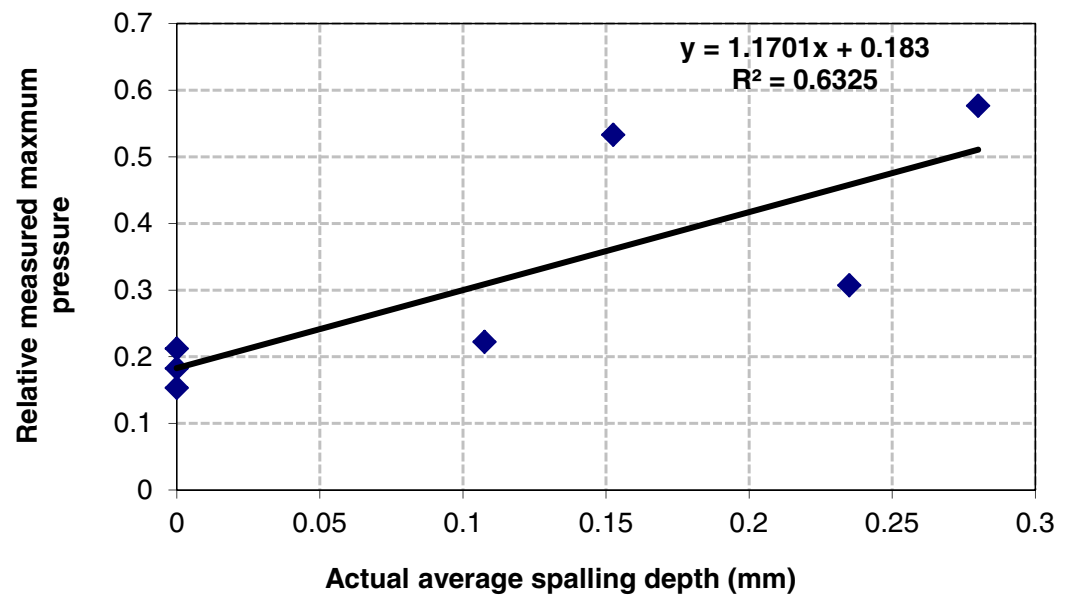

Figure 4. Relationship between relative measured maximum pressures and actual average spalling depth in fibrereinforced concrete series.

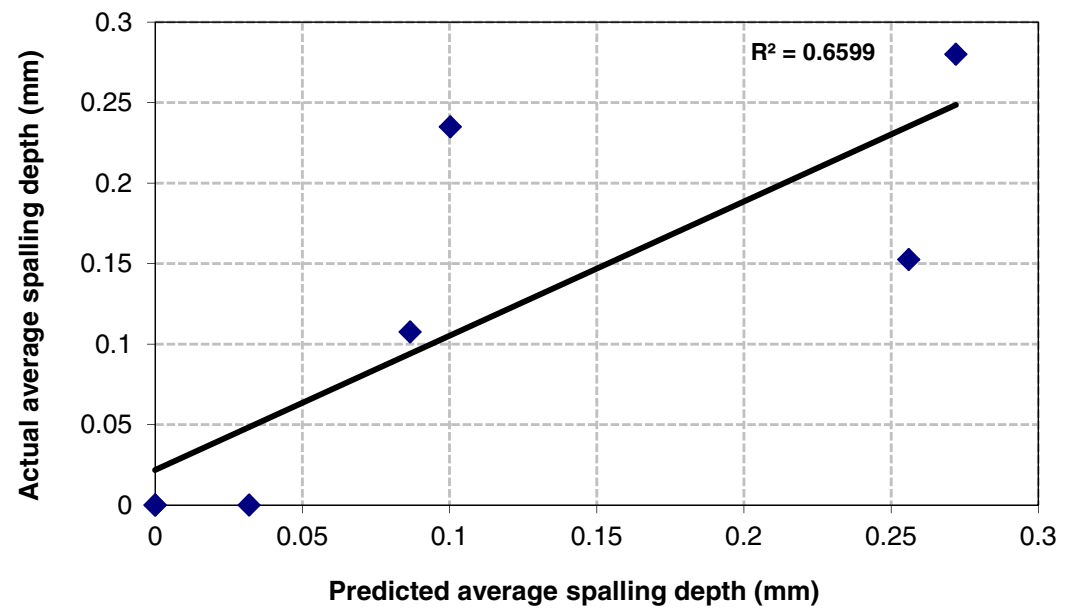

Figure 5. Relationship between actual and predicted average spalling depths in fibre-reinforced concrete series.

\section{CONCLUSIONS}

Useful information is proposed for safeguarding against spalling in concrete structures during fires by means of addition of organic fibres of different types and geometries for different concrete mixes. Therefore, when equipped with information about the maximum pressures in Plain HSC, strength of concrete as well as fibre geometry and type, it is possible to roughly predict the expected maximum pressures and average spalling depths in heated fibre-reinforced concrete. Furthermore, it is possible to come up with concrete mixture proportions capable of minimizing the expected maximum pressures in heated concrete to acceptable levels hence safeguarding against spalling in concrete structures during fires. A threshold relative maximum pore pressure of $0.183(0.92 \mathrm{MPa})$ has been suggested above which spalling is likely to occur. 


\section{MATEC Web of Conferences}

\section{References}

[1] Phan T.L., High - strength Concrete at High Temperature - An Overview, Utilisation of High Strength/High performance Concrete, $6^{\text {th }}$ International symposium. Proceedings. Volume 1. Leipzig, Germany, 2002.

[2] Consolazio G.R., McVay M. C., Rish J.W., Measurement and Prediction of pore pressure in Cement Mortar Subjected to elevated Temperature, NIST SP, September 1997, International workshop on Fire Performance of High-Strength Concrete. Proceedings, 125-148, 1997.

[3] Kalifa P., Menneteau F.D., Quenard D., Spalling and Pore Pressure in HPC at high temperatures, Cement and Concrete Research, 30, 1915 - 1927, 2000.

[4] Mugume R.B., Horiguchi T., Effect of fibre type and geometry on maximum pore pressures in fibre-reinforced high strength concrete at elevated temperatures, Cement and Concrete Research, 42, 459-466, 2012.

[5] Kalifa P., Chene G., Galle G., High temperature behaviour of HPC with polypropylene fibres From spalling to microstructure, Cement and Concrete Research, 31, 1487-1499, 2001.

[6] Phan T.L., Pore pressure and explosive spalling in concrete, Materials and Structures, 41, 16231632, 2008.

[7] Han C.G., Hwang Y.S., Gowripalan N., Performance of spalling resistance of high performance concrete with polypropylene fiber contents and lateral confinement, Cement and Concrete Research, 35, 1747-1753, 2005.

[8] Knack I., New PP-fibre with exceptional melting characteristics for improved fire protection in concrete building, 1st International Workshop on Concrete Spalling Due to Fire Exposure, Leipzig Germany, 238-247, 2009. 